\title{
SIMULATION OF BALLISTIC IMPACT ON POLYMER MATRIX COMPOSITE PANELS
}

\author{
DU LONG \\ Hongdu Aviation Industry Group, Nanchang, Jiangxi, China \\ e-mail: dragon7519_paper@sina.com
}

Composite panels, for example fuselage skins or wing skins of military aircraft, may be subjected to a variety of ballistic impacts. It is meaningful to understand the mechanical response, damage evolution and residual velocity of a projectile for panels under ballistic impact. In this paper, the numerical simulation method of ballistic impact on a laminated composite panel is considered. A rate-dependent material model based on the continuum damage mechanics concept is developed for polymer matrix composite materials. A full three-dimensional finite element model implemented with the material model is built up using material subroutine. The ballistic impact behavior is simulated employing an explicit dynamic finite element analysis technique. The effects of projectile size and velocity, layup of the composite panel, and failure criteria used on the ballistic impact response are investigated.

Keywords: composite materials, ballistic impact, material model, finite element modeling

\section{Introduction}

Fiber-polymer composites are ideal for a wide range of military and civil applications, where the weight is a very important aspect. For example, composite laminates have been widely used to produce aircraft fuselage or wing skins. Composite skins undergo various impact loadings during the service life: low velocity impact such as a tool dropped on the surface, high velocity impact such as bird strike. For the utilization of composites as military aircraft or protective structures, the resistance to ballistic impact is very important. Investigation on the projectile impact behavior, such as impact damage initiation and propagation as well as ballistic limit, are the foundation of personnel and structural survivability analysis.

The support conditions have important influence on the impact response in low velocity impact regime, but the response of the structural element is generally independent of its support conditions in high velocity impact (Naik and Shrirao, 2004). So far, there are many experimental studies on the ballistic impact of composite materials (Mouritz, 2001; Hosur et al., 2004; Ubeyli et al., 2007; Wiśniewski and Pacek, 2013). Tests confirmed that the ballistic limit of polymer composite plates increases with decreasing strength of the matrix shear (Karthikeyan et al., 2013). There is a direct proportionality between velocity and trace depth for polymer-based composites (Tarim et al., 2002). The major energy dissipation mechanisms during ballistic impact include elastic deformation of composites, failure of fibers, delamination and matrix cracking (Morye et al., 2000).

There have been several theoretical models that describe the ballistic impact on composites, see rg. Phoenix and Porwal (2003). Niak et al. (2006) presented an analytical method to identify different damage and energy absorbing mechanisms during ballistic impact based on wave theory. The analysis results show that shear plugging is the major energy absorbing mechanism (Naik and Doshi, 2008). Shirley et al. (2012) developed a nondimensional formulation to investigate the ballistic behavior of composite plates. The energy absorbed by shear plugging and 
friction are ignored in this model. Among the current ballistic impact models, many hypotheses are proposed, or the parameters should be determined by experimental data. Currently, finite element method (FEM) has been used to simulate high velocity impact behavior of composites by some researchers. Gower et al. (2008) simulated the ballistic impact response of laminated Kevlar composite panels used LS-DYNA. It is observed that the results are significantly influenced by the shape of projectile nose. Sheikh et al. (2009) used FEM to investigate the behavior of multiple laminated panels subjected to projectile impact of a compressed air gun. The laminates were modeled with quadrilateral shell elements.

In the present study, FEM is employed to study the ballistic impact behavior of polymer composite panels. Three-dimensional failure criteria and damage constitutive including strain rate effects are used to simulate the damage of composite laminates. The contact and penetration process as well as damage evolution mechanisms are investigated. Possible effects of various parameters on the ballistic impact behavior of composite panels are presented.

\section{Materials model}

Different from the conventional plane-stress assumption, the out-of-plane stresses have great influence in impact problems. On the other hand, there are various types of damage occurring during a ballistic impact, and the growth of these damages is coupled. Therefore, it is necessary to develop an appropriate three-dimensional material model to accurately simulate the progressive damage of composite panels under the ballistic impact.

Suppose the stress tensor in each material point is $\boldsymbol{\sigma}^{t}$ at time $t$. From time $t$ to $t+\Delta t$, the stress increment is $\Delta \boldsymbol{\sigma}^{t}$. So the stress tensor at the time $t+\Delta t$ can be calculated as

$$
\sigma^{t+\Delta t}=\sigma^{t}+\Delta \sigma^{t}
$$

In the micro-time range $\Delta t$, the stress increment $\Delta \boldsymbol{\sigma}^{t}$ is given by

$$
\Delta \sigma_{i j}^{t}=C_{i j k l}^{t} \Delta \varepsilon_{k l}^{t}
$$

Here $\Delta \varepsilon_{k l}^{t}$ denotes the strain increment, and $C_{i j k l}^{t}$ is the stiffness coefficient at the time $t$.

Based on continuum damage mechanics, three damage variables $D_{f}, D_{m}$ and $D_{i}$ are introduced to describe the fiber failure, matrix damage and interlaminar fracture modes, respectively. Then the damaged stiffness coefficients at the time $t$ have the forms

$$
\begin{array}{ll}
C_{1111}^{t}=\left(1-D_{f}\right) E_{1}^{t} \frac{1-\mu_{23} \mu_{32}}{C_{0}} & C_{2222}^{t}=\left(1-D_{m}\right) E_{2}^{t} \frac{1-\mu_{13} \mu_{31}}{C_{0}} \\
C_{3333}^{t}=\left(1-D_{i}\right) E_{3}^{t} \frac{1-\mu_{12} \mu_{21}}{C_{0}} & C_{1122}^{t}=\left(1-D_{f}\right)\left(1-D_{m}\right) E_{1}^{t} \frac{\mu_{21}+\mu_{31} \mu_{23}}{C_{0}} \\
C_{2211}^{t}=C_{1122}^{t} & C_{1133}^{t}=\left(1-D_{f}\right)\left(1-D_{i}\right) E_{1}^{t} \frac{\mu_{31}+\mu_{21} \mu_{32}}{C_{0}} \\
C_{3311}^{t}=C_{1133}^{t} & C_{2233}^{t}=\left(1-D_{m}\right)\left(1-D_{i}\right) E_{2}^{t} \frac{\mu_{32}+\mu_{31} \mu_{12}}{C_{0}} \\
C_{3322}^{t}=C_{2233}^{t} & C_{2323}^{t}=\left(1-D_{f}\right)\left(1-D_{m}\right) G_{12}^{t} \\
C_{3131}^{t}=\left(1-D_{m}\right)\left(1-D_{i}\right) G_{23}^{t} & C_{1212}^{t}=\left(1-D_{f}\right)\left(1-D_{i}\right) G_{13}^{t} \\
C_{0}=1-\mu_{12} \mu_{21}-\mu_{13} \mu_{31}-\mu_{23} \mu_{32}-2 \mu_{21} \mu_{32} \mu_{13}
\end{array}
$$

where

$$
D_{k}=1-\left(1-D_{k T}\right)\left(1-D_{k C}\right) \quad k=f, m, i
$$


Here, $D_{k T}$ and $D_{k C}(k=f, m, i)$ denote the damage factors corresponding to fiber, matrix and interlaminar tensional failure and compression failure, respectively.

During ballistic impact, the loading on the composite structure is dynamic. Much previous research efforts related to high strain rate loading has indicated that the properties of polymer composite materials are strain rate-dependent - the elastic modulus and strength change with the applied rate of loading (Hosur et al., 2001; Okenwa, 2001; Amos et al., 2002; Naik et al., 2007; Tarfaoui et al., 2008). So the strain rate effect should be considered in the material model for ballistic impact simulation of composite panels. Here, it is thought that all of the moduli vary linearly with the logarithm of strain rate as follows (Daniel et al., 2011):

$$
E^{t}(\dot{\varepsilon})=E\left(\dot{\varepsilon}_{0}\right)\left[m_{e} \log \left(\frac{\dot{\varepsilon}^{t}}{\dot{\varepsilon}_{0}}\right)+1\right]
$$

where $E$ represents the elastic modulus or shear modulus, $m_{e}$ is the correction coefficient of strain-rate hardening, $\dot{\varepsilon}^{t}$ is the strain rate at the time $t, \dot{\varepsilon}_{0}$ denotes the reference strain rate.

There are many criteria to predict failure initiation of composite materials (Huang and Zhou, 2011). Hashin's criterion can identify different modes of failure: tensile fiber failure, compressive fiber failure, tensile matrix failure and compressive matrix failure. It may be implemented in a finite element program to carry out the progressive failure analysis of composite panels under ballistic impact. The three-dimensional Hashin failure criteria are expressed as follows:

i) fiber failure modes

$$
\begin{aligned}
& \left(\frac{\sigma_{11}}{X_{T}^{t}}\right)^{2}+\alpha\left(\frac{\sigma_{12}}{S_{12}^{t}}\right)^{2}+\alpha\left(\frac{\sigma_{13}}{S_{13}^{t}}\right)^{2} \geqslant 1 \quad \text { if } \quad \sigma_{11} \geqslant 0 \\
& \left(\frac{\sigma_{11}}{X_{C}^{t}}\right)^{2} \geqslant 1 \quad \text { if } \quad \sigma_{11}<0
\end{aligned}
$$

ii) matrix damage modes

$$
\begin{aligned}
& \left(\frac{\sigma_{22}+\sigma_{33}}{Y_{T}^{t}}\right)^{2}+\frac{\sigma_{23}^{2}-\sigma_{22} \sigma_{33}}{S_{23}^{t 2}}+\left(\frac{\sigma_{12}}{S_{12}^{t}}\right)^{2}+\left(\frac{\sigma_{13}}{S_{13}^{t}}\right)^{2} \geqslant 1 \quad \text { if } \quad \sigma_{22}+\sigma_{33} \geqslant 0 \\
& \left(\frac{\sigma_{22}+\sigma_{33}}{2 S_{23}^{t}}\right)^{2}+\left[\left(\frac{Y_{C}}{2 S_{23}^{t}}\right)^{2}-1\right] \frac{\sigma_{22}+\sigma_{33}}{Y_{C}^{t}}+\frac{1}{S_{23}^{t 2}}\left(\sigma_{23}^{2}-\sigma_{22} \sigma_{33}\right)+\left(\frac{\sigma_{12}}{S_{12}^{t}}\right)^{2}+\left(\frac{\sigma_{13}}{S_{13}^{t}}\right)^{2} \geqslant 1 \\
& \quad \text { if } \quad \sigma_{22}+\sigma_{33}<0
\end{aligned}
$$

The Quads criteria (Camanho and Davila, 2002) are adopted to predict the initiation and subsequent propagation of interlaminar damage

$$
\begin{aligned}
& \left(\frac{\sigma_{33}}{Z_{T}^{t}}\right)^{2}+\left(\frac{\sigma_{13}}{S_{13}^{t}}\right)^{2}+\left(\frac{\sigma_{23}}{S_{23}^{t}}\right)^{2} \geqslant 1 \quad \text { if } \quad \sigma_{33} \geqslant 0 \\
& \left(\frac{\sigma_{13}}{S_{13}^{t}}\right)^{2}+\left(\frac{\sigma_{23}}{S_{23}^{t}}\right)^{2} \geqslant 1 \quad \text { if } \quad \sigma_{33}<0
\end{aligned}
$$

In the above equations, $X_{T}^{t}, X_{C}^{t}, Y_{T}^{t}, Y_{C}^{t}, Z_{T}^{t}, Z_{C}^{t}, S_{12}^{t}, S_{13}^{t}$ and $S_{23}^{t}$ are the different strength components at the time $t$. Here, all of the strength components are functions of the strain rate

$$
F^{t}(\dot{\varepsilon})=F\left(\dot{\varepsilon}_{0}\right)\left[m_{f} \log \left(\frac{\dot{\varepsilon}^{t}}{\dot{\varepsilon}_{0}}\right)+1\right]
$$

where $m_{f}$ is the correction coefficient of strain-rate hardening. 


\section{Finite element model}

A finite element model has been created for a composite panel under ballistic impact as shown in Fig. 1. A quarter panel of dimension $100 \mathrm{~mm} \times 100 \mathrm{~mm} \times 1.5 \mathrm{~mm}$ is modeled with $36.3 \mathrm{k}$ 8-node brick elements. The mechanical constitutive behavior and failure theory of the three-dimensional composites element, which have been previously described, are defined with material subroutine complied by Intel Fortran Compiler (ver 9.1). The mechanical properties of T300/NY9200GA epoxy composites used in the analysis are presented in Table 1.

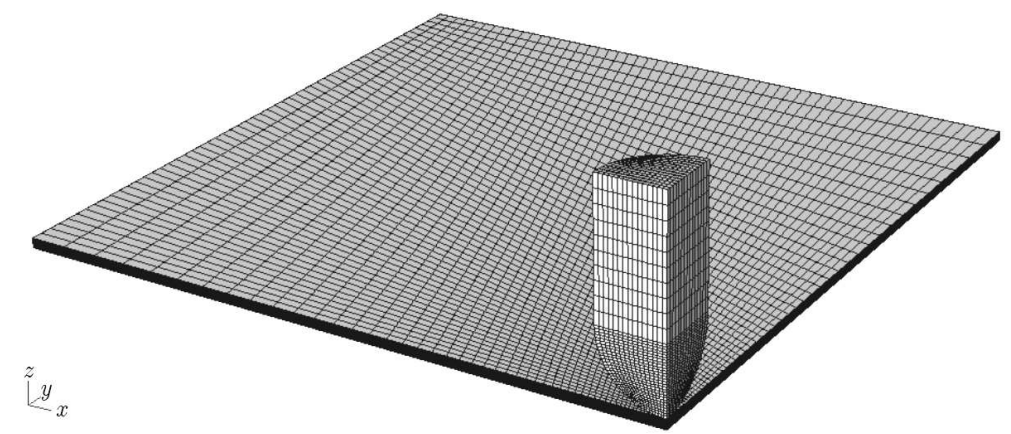

Fig. 1. Finite element model of ballistic impact on the composite panel

Table 1. Mechanical properties of T300/NY9200GA epoxy composites

\begin{tabular}{|c|c|c|c|c|c|c|c|c|}
\hline $\begin{array}{c}E_{1} \\
{[\mathrm{MPa}]}\end{array}$ & $\begin{array}{c}E_{2} \\
{[\mathrm{MPa}]}\end{array}$ & $\begin{array}{c}E_{3} \\
{[\mathrm{MPa}]}\end{array}$ & $\begin{array}{c}G_{12} \\
{[\mathrm{MPa}]}\end{array}$ & $\begin{array}{c}G_{13} \\
{[\mathrm{MPa}]}\end{array}$ & $\begin{array}{c}G_{23} \\
{[\mathrm{MPa}]}\end{array}$ & $\mu_{12}$ & $\mu_{13}$ & $\mu_{23}$ \\
\hline 124000 & 7500 & 7500 & 4600 & 4600 & 3500 & 0.31 & 0.31 & 0.36 \\
\hline $\begin{array}{c}X_{t} \\
{[\mathrm{MPa}]}\end{array}$ & $\begin{array}{c}X_{C} \\
{[\mathrm{MPa}]}\end{array}$ & $\begin{array}{c}Y_{t} \\
{[\mathrm{MPa}]}\end{array}$ & $\begin{array}{c}Y_{C} \\
{[\mathrm{MPa}]}\end{array}$ & $\begin{array}{c}Z_{t} \\
{[\mathrm{MPa}]}\end{array}$ & $\begin{array}{c}Z_{C} \\
{[\mathrm{MPa}]}\end{array}$ & $\begin{array}{c}S_{12} \\
{[\mathrm{MPa}]}\end{array}$ & $\begin{array}{c}S_{13} \\
{[\mathrm{MPa}]}\end{array}$ & $\begin{array}{c}S_{23} \\
{[\mathrm{MPa}]}\end{array}$ \\
\hline 1420 & 913 & 35 & 130 & 45 & 180 & 60 & 60 & 35 \\
\hline$\overline{\overline{D_{f T}}}$ & $\overline{\overline{D_{f C}}}$ & $\overline{D_{m T}}$ & $\overline{D_{m C}}$ & $\overline{\overline{D_{i T}}}$ & $\overline{\overline{D_{i C}}}$ & & & \\
\hline 0.9 & 0.9 & 0.8 & 0.6 & 0.8 & 0.6 & & & \\
\hline
\end{tabular}

The round cone ended projectile is modeled with 8.294k 8-node brick elements, and the freedoms except the displacement along impact direction are fixed. The density of the projectile is $7.81 \mathrm{~g} / \mathrm{cm}^{3}$, Young's modulus is $210 \mathrm{GPa}$ and Poisson's ratio is 0.3 .

The nodes along the exterior sides of the panel are fixed in the $x, y, z$ directions, and symmetric boundary conditions are applied along the planes of symmetry. The penalty contact algorithm is used to model the contact behavior between the projectile and panel. One surface is defined as the "master" surface and the other one as the "slave" surface. This method applies virtual springs to surfaces in contact to calculate the restorative force at the point of penetration between the two bodies. The contact force is in direct proportion to penetration depth and materials stiffness.

An explicit dynamic analysis technique is employed to simulate the ballistic impact behavior of the composite panel. The equations of motion are integrated using the explicit centraldifference integration rule.

\section{Numerical analysis results and discussions}

Figure 2 shows the damage evolution of the composite laminates under ballistic perforation as a function of time. The stacking sequence of laminates is $\left[45^{\circ} /-45^{\circ} / 0^{\circ} / 90^{\circ} /-45^{\circ} / 45^{\circ}\right]_{S}$ (layup I), and the radius of nose is $10 \mathrm{~mm}$. The projectile completely goes across the composite panels with 

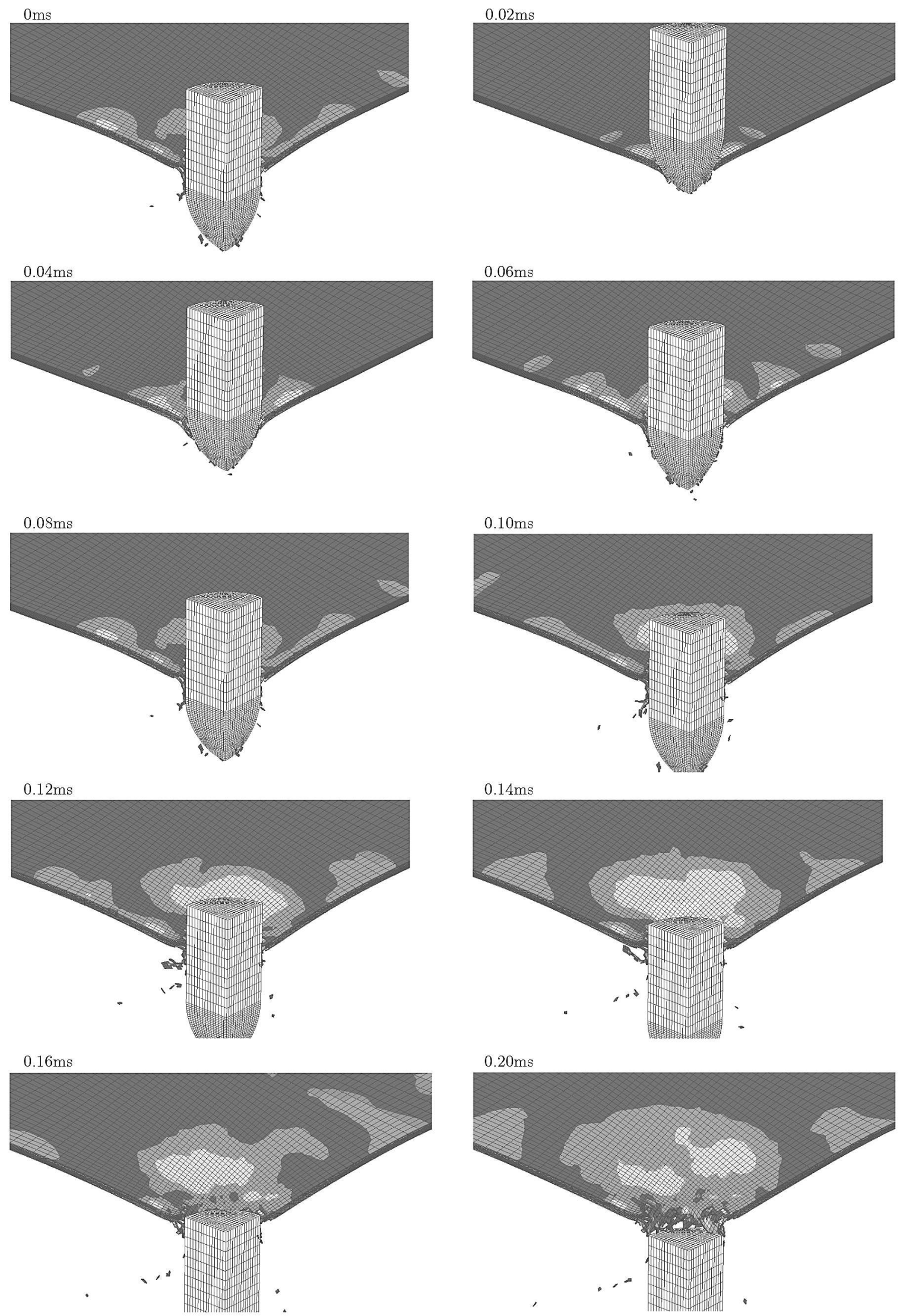

Fig. 2. Damage evolution process of the composite panel under ballistic impact 
an impact velocity of $200 \mathrm{~m} / \mathrm{s}$. When the projectile contacts the composite panel, the layer under the projectile undergoes shock compression at once, the stress exceeds the crushing strength, and the damage occurs. Different from thick panels, the damage develops and propagates to the reverse side of the laminates instantly for thin panels. Delamination and tensile or bending failure appear in the rear part very shortly from the time the contact is formed. The damage region does not extend if the nose penetrates the composite panel. The final damage regions near the upper and lower surfaces are bigger than those in the middle layers.

Different types of damage couple and competitively and unstably grow for the composite panel under ballistic impact. Figure 3 presents variation of the damage area with time for composite layup I. The area corresponding to the matrix damage is bigger than that of delamination, and the fiber failure area is smaller than that of delamination during the initial period of time from $0 \mathrm{~ms}$ to $0.01 \mathrm{~ms}$.

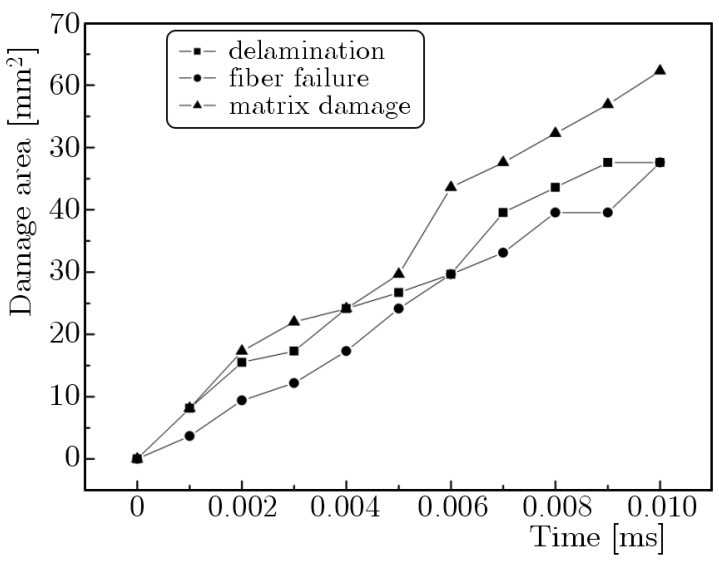

Fig. 3. Variation of the damage area versus time

Figure 4 illustrates variation of the contact force with time for the constant projectile nose radius $(10 \mathrm{~mm}$ ) and composite layup (layup I). The contact force reaches a maximum in a short time and decreases to zero when the projectile perforates the panel. Three different velocities of the projectile, $200 \mathrm{~m} / \mathrm{s}, 250 \mathrm{~m} / \mathrm{s}, 300 \mathrm{~m} / \mathrm{s}$ are used in these analyses. The maximal contact forces during penetration are $2.06 \mathrm{kN}, 2.31 \mathrm{kN}$, and $3.27 \mathrm{kN}$, respectively. It indicates that the maximal contact force nonlinearly increases with velocity of the projectile.

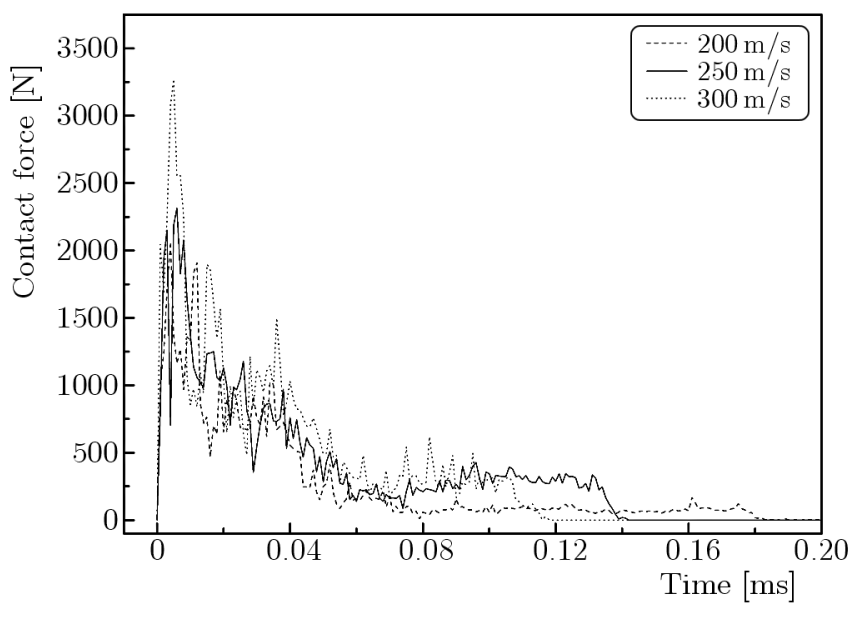

Fig. 4. Variation of the contact force versus time

Figure 5 displays variation of the contact area versus time. Here, the projectile nose radius is $10 \mathrm{~mm}$, and the initial impact velocity is $200 \mathrm{~m} / \mathrm{s}$. Different layups are investigated in these 
analyses. The stacking sequence of layup II is $\left[45^{\circ} /-45^{\circ} / 0^{\circ} / 90^{\circ} / 0^{\circ} / 0^{\circ}\right]_{S}$. Layup I and II have the same laminate thickness but different ply proportions. The distribution and propagation of damages depend on the laminates thickness, ply angle and stacking sequence. The layup has obvious influence on the contact behavior between the projectile and panel. The fluctuation of the contact area reflects the durative initiation and expansion of various damages.

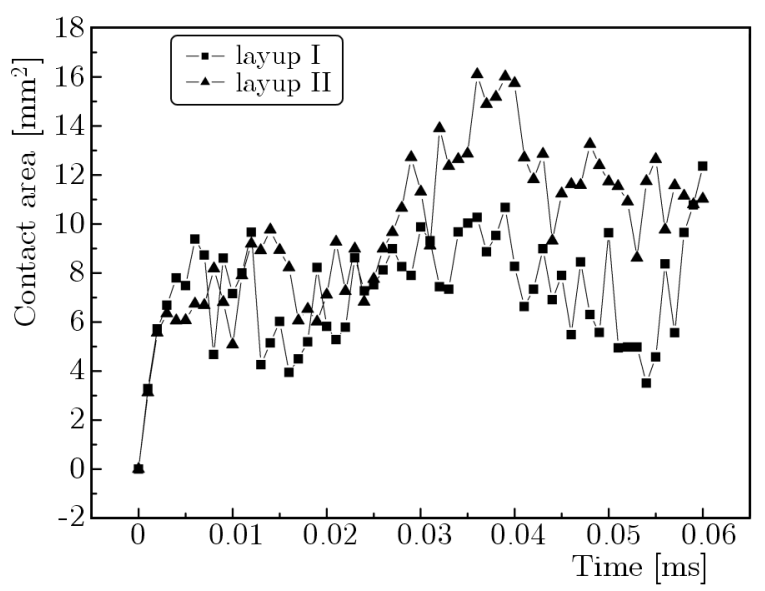

Fig. 5. Variation of the contact area versus time

The stress histories of the reference element for three different radii of the projectile noses are shown in Fig. 6. The stress is partly but strongly dependent on the nose radius of the projectile. For the projectiles with $6 \mathrm{~mm}$ and $8 \mathrm{~mm}$ radius noses, the stress variation trends are similar. It is different from that of projectile with a $10 \mathrm{~mm}$ radius nose. The reference element fails soon under ballistic impact because it is near the projectile nose if the $10 \mathrm{~mm}$ radius nose is used.

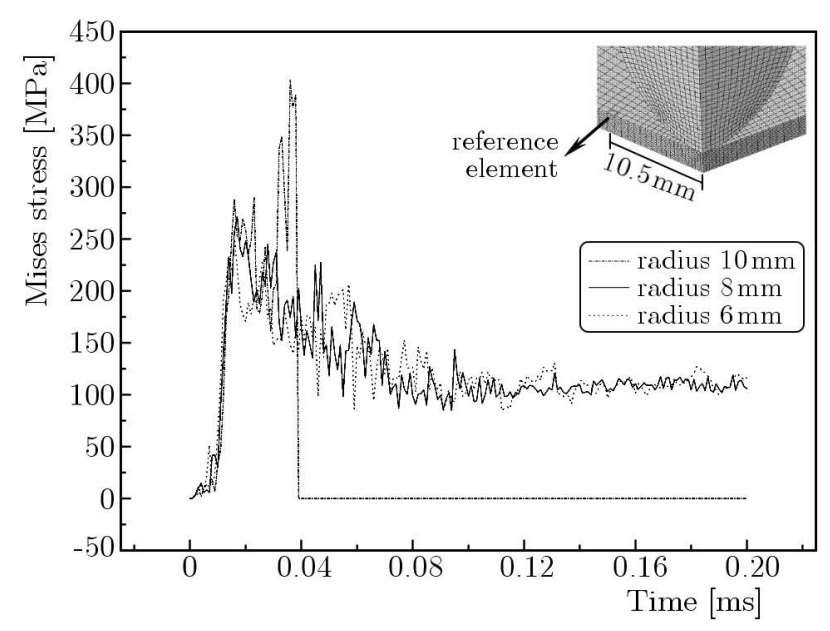

Fig. 6. Variation of the stress versus time for the reference element

The maximum strain failure criterion has also been used to model the failure behavior of composite materials under ballistic impact. Figure 7 shows variation of the kinetic energy versus time for different failure criteria. More kinetic energy loss is observed when the maximum strain failure criterion is used, although the difference only is $3 \%$.

For the fixed initial velocity at $200 \mathrm{~m} / \mathrm{s}$, the residual velocities of projectiles have been investigated for different cases. The results are shown in Fig. 8. The residual velocities of projectiles are $197.95 \mathrm{~m} / \mathrm{s}, 197.84 \mathrm{~m} / \mathrm{s}$ and $197.44 \mathrm{~m} / \mathrm{s}$ for $10 \mathrm{~mm}, 8 \mathrm{~mm}$ and $6 \mathrm{~mm}$ radius nose, respectively. It is proved that the residual velocity of projectile increases nonlinearly with nose radius. The residual velocity of the projectile with $10 \mathrm{~mm}$ radius nose for layup II is $197.79 \mathrm{~m} / \mathrm{s}$. It indicates that the capability against ballistic impact for layup II is slightly better than that for layup I. 


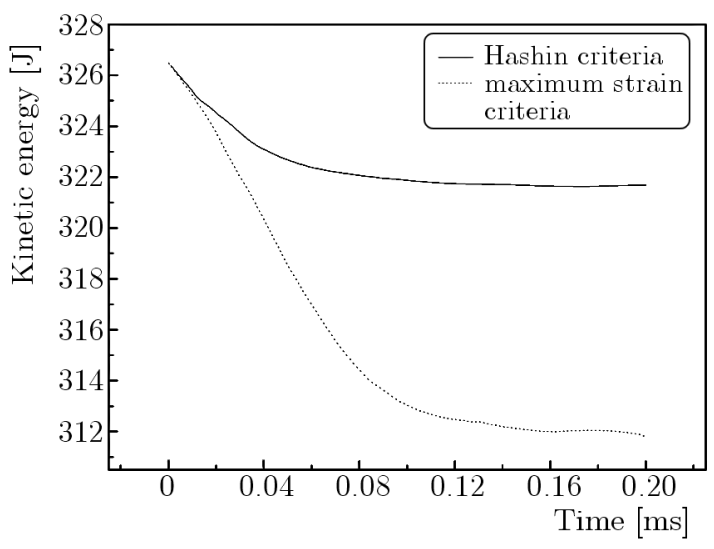

Fig. 7. Variation of the kinetic energy versus time

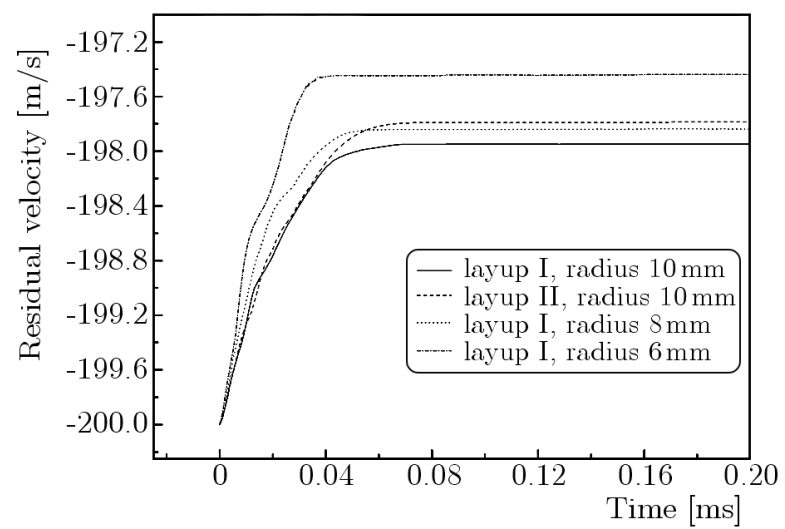

Fig. 8. Comparison of the residual velocity of projectile/time curves

Figure 9 shows the stress along the neutral axis, the intersecting line of the neutral plane and symmetrical plane of panel at different times. The elements close to the impact point have failed, so the stress values are zero. The stress reaches the maximum value sharply and then gradually declines to a constant value along the neutral axis. At the times of $2 \mathrm{~ms}, 2.5 \mathrm{~ms}$ and $3 \mathrm{~ms}$, the maximum value of stress is increased from $123.5 \mathrm{MPa}$ to $244.6 \mathrm{MPa}$, and then to $330.1 \mathrm{MPa}$.

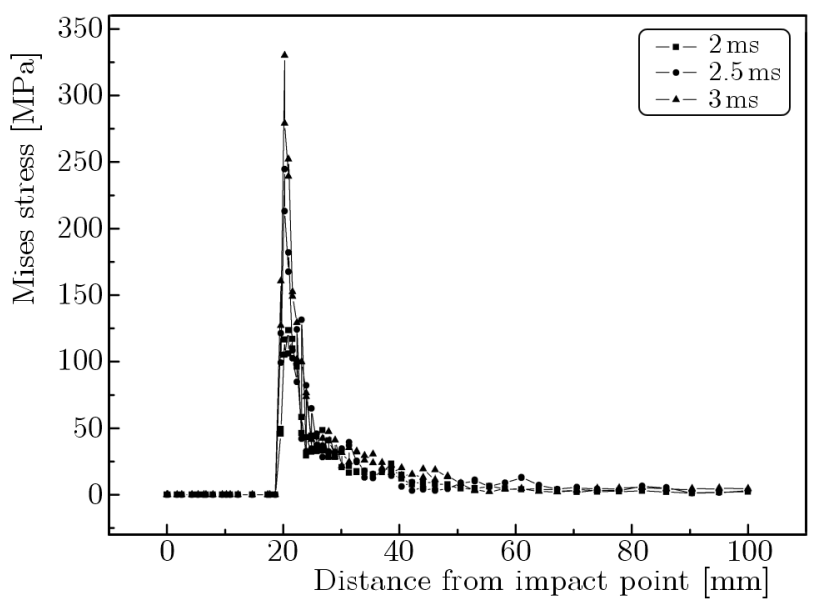

Fig. 9. Variation of Mises stress along the neutral axis

Figure 10 shows the deformation of the projectile nose vertex versus time. Besides using a steel projectile, aluminium alloy projectile $\left(\rho=2.7 \mathrm{~g} / \mathrm{cm}^{3}, E=72 \mathrm{GPa}, \nu=0.3, \sigma_{y}=390 \mathrm{MPa}\right)$ 
has also been considered in this demonstration. It can be seen that the changes in the shape of the projectile nose during penetration is very small for the thin composite panel, which is generally used as aircraft skin. This is different from penetration of thick ductile composites for example thick-section aramid fabrics.

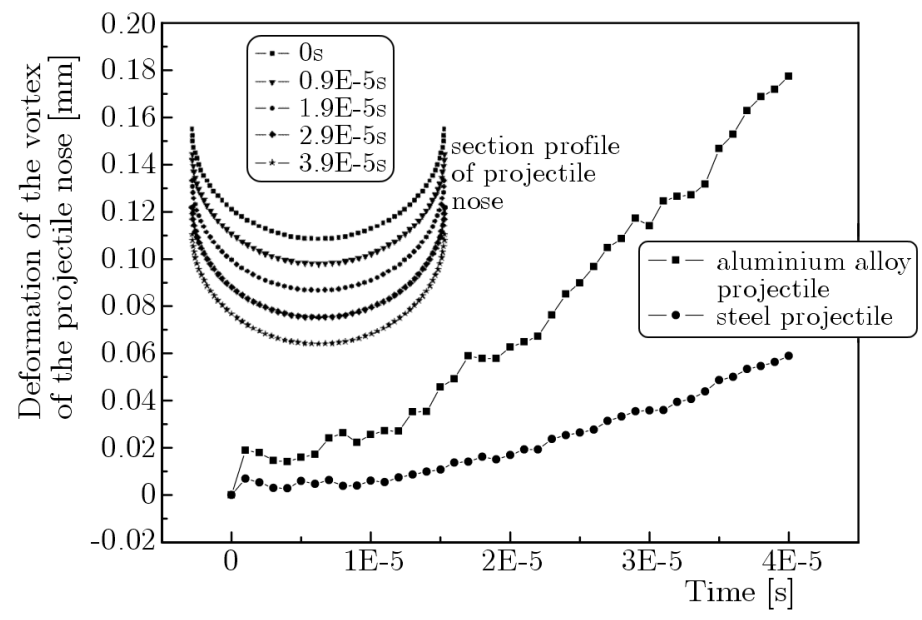

Fig. 10. Deformation of the vertex of the projectile nose versus time

\section{Conclusions}

In this paper, a rate-dependent material model based on the continuum damage mechanics concept for failure mechanism of polymer matrix composites has been developed. A three-dimensional finite element model implemented with the material model has been developed to model laminated composite panel. The explicit dynamic finite element analysis technique has been employed to simulate the ballistic impact behavior. The stress increment has been solved in every incremental time step, and the stress and element state have been updated at the end of each step.

A numerical study of ballistic impact on laminated polymer composite panel has been presented. The results indicate that the dimension or initial velocity of projectile, layup of laminated panel, and selective failure criterion of composite materials have significant influences on the dynamic response and failure behavior of laminated composite panel upon ballistic impact.

\section{References}

1. Amos G., Robert K.G., Gary D.R., 2002, Experimental study of strain-rate-dependent behavior of carbon/epoxy composite, Composites Science and Technology, 62, 10/11, 1469-1476

2. Camanho P.P., Davila C.G., 2002, Mixed-mode decohesion finite elements for the simulation of delamination in composite materials, NASA/TM-2002-211737

3. Daniel I.M., Werner B.T., Fenner J.S., 2011, Strain-rate-dependent failure criteria for composites, Composites Science and Technology, 71, 3, 357-364

4. Gower H.L., Cronin D.S., Plumtree A., 2008, Ballistic impact response of laminated composite panels, International Journal of Impact Engineering, 35, 9, 1000-1008

5. Hosur M.V., Alexander J., Vaidya U.K., Jeelani S., 2001, High strain rate compression response of carbon/epoxy laminate composites, Composite Structures, 52, 3/4, 405-417

6. Hosur M.V., Vaidya U.K., Ulven C., Jeelani S., 2004, Performance of stitched/unstitched woven carbon/epoxy composites under high velocity impact loading, Composite Structures, 64, $3 / 4,455-466$ 
7. Huang Z.M., Zhou Y.X., 2011, Strength of Fibrous Composites, Hang Zhou

8. Karthikeyan K., Russell B.P., Fleck N.A., Wadley H.N.G., Deshpande V.S., 2013, The effect of shear strength on the ballistic response of laminated composite plates, European Journal of Mechanics - A/Solids, 42, 35-53

9. Morye S.S., Hine P.J., Duckett R.A., Carr D.J., Ward I.M., 2000, Modelling of the energy absorption by polymer composites upon ballistic impact, Composites Science and Technology, 60, 14, 2631-2642

10. Mouritz A.P., 2001, Ballistic impact and explosive blast resistance of stitched composites, Composites Part B: Engineering, 32, 5, 431-439

11. Naik N.K., Asmelash A., Kavala V.R., Veerraju C., 2007, Interlaminar shear properties of polymer matrix composites: Strain rate effect, Mechanics of Materials, 39, 12, 1043-1052

12. NAIK N.K., Doshi A.V., 2008, Ballistic impact behaviour of thick composites: Parametric studies, Composite Structures, 82, 3, 447-464

13. NAIK N.K., Shrirao P., 2004, Composite structures under ballistic impact, Composite Structures, 66, $1 / 4,579-590$

14. NAik N.K., Shrirao P., Reddy B.C.K., 2006, Ballistic impact behaviour of woven fabric composites: Formulation, International Journal of Impact Engineering, 32, 9, 1521-1552

15. OKenwa I.O., 2001, The effect of strain rate and failure modes on the failure energy of fibre reinforced composites, Composite Structures, 54, 2/3, 299-303

16. Phoenix S.L., Porwal P.K., 2003, A new membrane model for ballistic impact response and V50 performance of multi-ply fibrous systems, International Journal of Solids and Structures, 40, 24, 6723-6765

17. Sheikh A.H., Bull P.H., Kepler J.A., 2009, Behaviour of multiple composite plates subjected to ballistic impact, Composites Science and Technology, 69, 6, 704-710

18. Shirley K., Castillo G., Sonia S.S., Barbero E., 2012, Nondimensional analysis of ballistic impact on thin woven laminate plates, International Journal of Impact Engineering, 39, 1, 8-15

19. Tarfaoui M., Choukri S., Neme A., 2008, Effect of fibre orientation on mechanical properties of the laminated polymer composites subjected to out-of-plane high strain rate compressive loadings, Composites Science and Technology, 68, 2, 477-485

20. TARim N., Findik F., Uzun H., 2002, Ballistic impact performance of composite structures, Composite Structures, 56, 1, 13-20

21. Ubeyli M., Yildirim R.O., Ogel B., 2007, On the comparison of the ballistic performance of steel and laminated composite armors, Materials and Design, 28, 4, 1257-1262

22. Wiśniewski A., PACEK D., 2013, Experimental research and numerical analysis of penetration of the Twaron T750 aramid fabric with the $9 \mathrm{~mm}$ Parabellum projectile, Problems of Mechatronics. Armament, Aviation, Safety Engineering, 3, 13, 7-22 